\title{
Protective effects of Curcuma longa rhizomes ethyl acetate extract against alcohol induced oxidative stress and nephrotoxicity in female Wistar rats
}

\author{
O.E. ETENG ${ }^{1 \bullet}$, C.A. MOSES ${ }^{1}$, J. ENOBONG ${ }^{1}$, A.J. AKAMO ${ }^{1}$, D.I. AKINLOYE ${ }^{1}$, R.N. UGBAJA ${ }^{1}$, \\ O.A. AKINLOYE ${ }^{2}$ \\ ${ }^{1}$ Department of Biochemistry, Federal University of Agriculture. Abeokuta, Ogun State, Nigeria. ^email: ofemeffiom@gmail.com \\ ${ }^{2}$ Department of Biochemistry, University of Calabar. Calabar, Nigeria
}

Manuscript received: 26 January 2020. Revision accepted: 4 February 2020.

\begin{abstract}
Eteng OE, Moses CA, Enobong J, Akamo AJ, Akinloye DI, Ugbaja RN, Akinloye OA. 2020. Protective effects of Curcuma longa rhizomes ethyl acetate extract against alcohol induced oxidative stress and nephrotoxicity in female Wistar rats. Biofarmasi J Nat Prod Biochem 18: 5-12. This study aimed to evaluate the protective effect of Curcuma longa Linn. (syn. Curcuma domestica Val.) rhizomes ethyl acetate extract (CLREAE) facing alcohol-induced oxidative stress and nephrotoxicity. Thirty female (30) Wistar rats were categorized randomly into six groups. Groups 1,2, 3, 4, 5 and 6 were treated with normal saline; $20 \%$ ethanol; $100 \mathrm{mg}$ of CLREAE + 20\% ethanol; $200 \mathrm{mg}$ of CLREAE + 20\%; $350 \mathrm{mg}$ of CLREAE + 20\% ethanol and $350 \mathrm{mg}$ of CLREAE respectively for 14 days. A significant $(\mathrm{p}<0.05)$ decrease in the SOD, CAT, and GPx activities and GSH concentration of rats treated with only $20 \%$ ethanol were found when compared to the normal control group, whereas a significant $(\mathrm{P}<0.05)$ increase in the groups pretreated with different doses of the CLREAE were also found when compared to groups with only $20 \%$ ethanol treatment. Thus, compared to the normal control group, treatment with the CLREAE fetched a significant $(\mathrm{p}<0.05)$ decrease in the renal biomarkers (creatinine and urea). Whilst, compared to the groups with $20 \%$ methanol treatment, a significant $(\mathrm{p}<0.05)$ increase happened in the groups pretreated with different doses of the CLREAE. There was a significant $(\mathrm{p}<0.05)$ decrease in Kidney MDA levels in rats pretreated with different doses of CLREAE compared with the normal control. The histology results showed a physiologic recovery in the kidney tissues as groups were treated with different doses of the CLREAE. This is evidenced by reduced necrosis of tubular and glomerular epithelial; the signs of protection against toxicity were found in the rats. The study suggested that through in vivo free radical scavenging ability, the CLREAE has protective effects against alcohol-induced oxidative stress and nephrotoxicity in female Wistar rats.
\end{abstract}

Keywords: Nephrotoxicity, Curcuma longa, oxidative stress, alcohol, ethyl acetate

\section{INTRODUCTION}

Nephrotoxicity is the toxicity in the kidneys, and it is caused by toxic chemicals or medications having poisonous effects on kidney function. Several studies have identified that risk factors for nephrotoxicity involve alcoholism, high blood pressure, diabetes mellitus, exposure to occupational nephrotoxins, and chronic use of analgesics (Knott et al. 1996). Alcohol and its metabolites go through the kidneys and are excreted into the urine, and its content in the urine is higher than that of the blood and the liver. The kidney is often involved in developing, maintaining, and counterregulation of complex electrolyte disturbances (Das et al. 2008).

As a risk factor for kidney damage, blood pressure is being raised by regular alcohol consumption. Abnormalities in kidney structure and function are reported to increase the frequency of fetal alcohol syndrome, as seen in children prenatally exposed to ethanol. The kidney is an organ that is efficiently designed to perform two main tasks in the body, namely the excretion of metabolic end products and the proper regulation of fluid body constituents (Guyton 1992). When the tasks are completed, the kidney forms and collects urine, passing through the ureter into the bladder (Rhoades and Pffanzer 1992).

Nephrotoxicity determines xenobiotic damaging effects on the kidneys. Alcohol consumption has been related to an aloft incidence of coronary heart disease (CHD) and chronic kidney disease (CKD) (Parekh et al. 2001). Alcohol toxicity is linked to metabolism through alcohol dehydrogenase $(\mathrm{ADH})$, which alters ethanol into toxic acetaldehyde, eventually oxidized to acetate through aldehyde dehydrogenase (ALDH). Acetaldehyde is a toxic by-product of ethanol metabolites that causes liver defects (Purohit et al. 2003). Acute alcohol poisoning or chronic alcoholism causes kidney disablement (Knott et al. 2015). Other studies also denounce similar conclusions, which show that the incidence of kidney disablement is comparable to or even lower in heavy drinkers (more than $210 \mathrm{~g} /$ week of alcohol consumption) than those in moderate drinkers (70-210 g/week of alcohol consumption) (Koning et al. 2015). On the contrary, several other studies have found that large amounts of alcohol consumption can predict worse outcomes in patients with chronic kidney sickness (White et al. 2009). For example, White and colleagues (Latchoumycandane et al. 2015) informed that heavier drinkers (those who consumed more than $30 \mathrm{~g}$ of alcohol/week) had a higher risk of developing 
albuminuria, which is usually a symptom of kidney sickness. There is increasing evidence that chronic ethanol exposure can cause functional conversions and structural disablement in the kidneys (Latchoumycandane et al. 2015).

Previous studies have observed that, from a functional perspective, after ethanol exposure, proximal tubular disorganization, microvilli disorientation, luminal casts, glomerular mesangial matrix expansion, and convoluted proximal tubule occlusion accompanied by partial degeneration were of proximal tubular cells, and reduced cell height cell will occur. While the mechanisms of alcohol-induced cell lesions and sicknesses are still being examined, recent research suggests that reactive oxygen species (ROS) may have a significant role. Reactive oxygen species can lead to various cellular wounds, such as DNA breakage, lipid peroxidation, and protein alteration. The cellular system is protected from ROS-generated cell wounds by a series of defenses consisting of various antioxidants with distinct functions. The presence of ROS in cellular systems will defeat the defense system, and they will generate oxidative stress or cell wound, which leads to the development of disease (Deodhar et al. 1980). ROS production is usually accompanied by the presence and cellular localization of anti-oxidant enzymes and thiol, such as superoxide dismutase (SOD), CAT, glutathione peroxidase (Gpx), and glutathione (GSH). The synthesis of GSH depends on ATP, but its reducing power depends on $\mathrm{NADPH}$ and the pentose phosphate pathway ( $\mathrm{Lu}$ et al. 2009). In vivo studies have discovered that accumulation of oxidative breakage emerging from lessened endogenous anti-oxidant degrees somewhat increases ROS production (Meng et al. 2007). Plant extracts containing natural antioxidants are recommended to improve kidney health status and lessen the risk of oxidative stress-based sicknesses.

Consequently, research has been carried out to reveal potential new sources of natural plant material. Over the years, many studies based on the utilization of natural compounds derived from plants as potential therapeutic agents for many sicknesses in humans have been carried out. Curcumin is a phenolic compound extracted from Curcuma longa Linn. (syn. Curcuma domestica Val.) rhizomes commonly utilized in Asia as seasonings, pigments, and additives. Several studies have reported that curcumin owns numerous biological functions, especially as antioxidants and anti-inflammation. Actually, it has been determined that curcumin is a bifunctional antioxidant; it mobilizes antioxidant activity directly and indirectly by scavenging reactive oxygen species and generates an antioxidant response severally. The renoprotective effect of curcumin has been assessed in numerous experimental models, including diabetic nephropathy, chronic kidney disablement, ischemia and reperfusion, and nephrotoxicity generated by compounds such as gentamicin, adriamycin, chloroquine, iron nitrilotriacetate, sodium fluoride, hexavalent chromium, and cisplatin. It has been reported lately in models of chronic kidney disablement that curcumin provides a therapeutic effect; indeed, it recovers systemic changes and glomerular hemodynamic alterations. Another recent finding indicates that the renoprotective effect of curcumin is related to the maintenance of mitochondrial function and redox balance. Together, these studies link the protective effects of curcumin in the kidney with the generation of the main regulator of the antioxidant response nuclear factor erythroid-derived 2 (Nrf2), restraint of mitochondrial dysfunction, weakening of the inflammatory response, keeping of antioxidant enzymes, and the avoidance of oxidative stress.

\section{MATERIALS AND METHODS}

\section{Apparatus and Biochemical instruments}

As equipment and biochemical instruments, the experiment utilized micropipettes, cotton wool, tissue paper, heparinized tubes, beakers, Eppendorf tubes, measuring tubes, conical flasks, disposable gloves, surgical kits, needles and syringes $(5 \mathrm{~mL}$ and $10 \mathrm{~mL})$, scales balance, spectrophotometer (Spectrum 23A), centrifuge, homogenizer, chloroform-methanol (2: 1v/v), diethyl ether, normal saline, distilled water, $0.05 \mathrm{M}$ potassium chloride $(\mathrm{KCl})$, creatine reagent kit, reagent kit all creatinine was purchased at the Libertas, Camp, Abeokuta laboratory services.

\section{Animals}

This study utilized thirty (30) female Wister mice weighing 150-220 $\mathrm{g}$ as experimental animals, which were obtained from the Tayo farm, Ajibode, Ibadan University, Ibadan. These animals were placed in well-ventilated wooden cages at room temperature $\left(28-30^{\circ} \mathrm{C}\right)$, with good lightening and humidity. Here, they were allowed to have free access to maximum feeding of animal feed and water ad libitum. They were acclimatized for two weeks before the experiment began. The animals were randomly separated into six groups of five animals each, as shown in Table 1. The administration was carried out using oral cannulas.

\section{Collection and preparation of plants}

Curcuma longa rhizomes were collected from the Ajasa farm, Idi-Ori Village, Ile-Ise Awo, Abeokuta, Nigeria. Plant specimens were validated by the Department of Botany, Federal Agricultural University, Abeokuta, as Curcuma longa (Family: Zingiberaceae). Plant specimens matched Herbarium specimens no: FUNAAB H-0065 (Meng et al. 2007). Turmeric has long been known as a spice, medicine, and coloring agent, and since 1280, Marco Polo has mentioned turmeric in his travels around China and India.

Table 1. Animal grouping

\begin{tabular}{ll}
\hline Groups & Treatment \\
\hline 1 & Control (normal saline) \\
2 & $20 \% \mathrm{Ethanol}$ only \\
3 & $\begin{array}{l}100 \mathrm{mg} / \mathrm{kg} \text { body weight of extract }+5.22 \mathrm{mg} / \mathrm{kg} \text { body } \\
\text { weight } 20 \% \text { ethanol }\end{array}$ \\
4 & $\begin{array}{l}200 \mathrm{mg} / \mathrm{kg} \text { body weight of extract }+5.22 \mathrm{mg} / \mathrm{kg} \text { body } \\
\text { weight } 20 \% \text { ethanol }\end{array}$ \\
5 & $\begin{array}{l}350 \mathrm{mg} / \mathrm{kg} \text { body weight of extract }+5.22 \mathrm{mg} / \mathrm{kg} \text { body } \\
\text { weight } 20 \% \text { ethanol }\end{array}$ \\
6 & $350 \mathrm{mg} / \mathrm{kg}$ body weight of extract \\
\hline
\end{tabular}



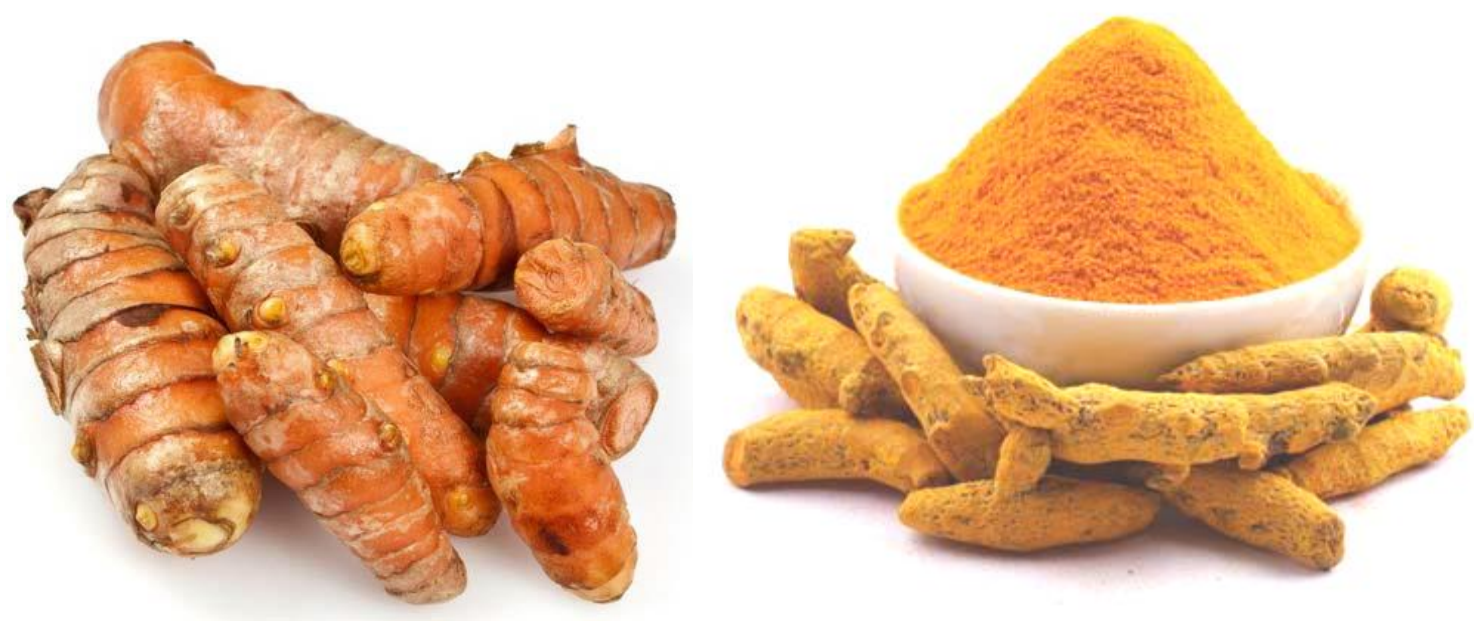

Figure 1. Turmeric rhizomes in (A) natural form and (B) grounded form

\section{Extraction of plant material}

The rhizomes were thoroughly rinsed, cut into small sizes, and dried with air to remove the moisture inside. After air-drying, the rhizomes were ground into powder using a mechanical blender. $1000 \mathrm{mg}$ of turmeric powder was weighed using analytical scales and treated with an appropriate solvent, ethyl acetate, measured to $2000 \mathrm{~mL}$. The mixture was left for 3 days in a shaker at room temperature. After that, the solution was filtered using Whatman No.1 filter paper. Next, the solvent was evaporated using a rotary evaporator under reduced pressure at a controlled temperature. The extract was stored for subsequent biochemical analysis.

\section{Experimental design}

The animals were separated into six groups which contained five animals each.

\section{Sacrifice}

Feed and water are taken from animals 24 hours before sacrificing process. Mice were lightly anesthetized with diethyl ether in a desiccator and then sacrificed.

\section{Blood collection}

Blood was collected from the inferior vena cava of the animal's heart, poured into a plain centrifuge tube, and left to stand for 1 hour. The serum was prepared by centrifugation at $4000 \mathrm{rpm}$ for 10 minutes in a centrifuge. For other biochemical tests, the clear supernatant was stored at $-4^{\circ} \mathrm{C}$.

\section{Organ Collecting}

The mice were then dissected from the abdomen to the thoracic area using surgical scissors and forceps. Important organs (kidneys) are then collected from mice, rinsed in normal saline, and stored in an ice cooler box.

\section{Homogenization of organs}

The collected kidneys were sliced to a weight of $0.2 \mathrm{~g}$ and homogenized in $1.8 \mathrm{~mL}$ of Sucrose-Tris-EDTA buffer.
These were then centrifuged at $4000 \mathrm{rpm}$ for 10 minutes, after which the supernatant was collected into an Eppendorf tube and stored in a cooler box.

\section{Statistical analysis}

Quantitative data were calculated using a one-way analysis of variance (ANOVA), followed by a post hoc test (Duncan) for significant values. A P-value of $<0.005$ was deemed statistically significant. Statistical analysis was done using statistical package software for social science (SPSS) version 20, while the graphs were plotted using Microsoft-Excel 08 software. Data were expressed as mean \pm standard error of the mean (SEM).

\section{RESULTS AND DISCUSSION}

The effect of ethyl acetate extract of $C$. longa on antioxidant parameters, namely GSH, GPx, catalase, and SOD, in the kidney of alcohol-generated female Wistar mice was shown in Table 2. Meanwhile, Figures 8-13 showed severe kidney necrosis led by treatment.

The level of MDA in plasma was significantly ( $\mathrm{P}$ $<0.05)$ declined in the groups treated with different doses of ethyl acetate extract of C. longa before treating $20 \%$ ethanol compared to animals with only 20\% alcohol administration. Still, when it was compared to the normal control group, there was a significant $(\mathrm{P}<0.05)$ increase in MDA level (Figure 2).

The MDA level in the kidney significantly $(\mathrm{P}<0.05)$ declined in the group pretreated with different doses of $C$. longa ethyl acetate extract before $20 \%$ ethanol treatment compared to animals treated with $20 \%$ alcohol alone, but there was a significant $(\mathrm{P}<0.05)$ increase when compared to the normal control group (Figure 3).

Treatment with extract caused a significant raise ( $\mathrm{P}$ $<0.05)$ of creatinine level in the kidney in the group which was given $20 \%$ ethanol only compared to the normal control group, but a significant decline $(\mathrm{P}<0.05)$ happened in the group given by initial treatment with different extract 
doses when compared to the group given only $20 \%$ ethanol (Figure 4).

Treatment with extract caused a significant decline in plasma level of creatinine $(\mathrm{P}<0.05)$ in the group administered only with $20 \%$ ethanol compared to the normal control group. Still, there was a significant raise ( $\mathrm{P}$ $<0.05)$ in the group initially administered with various extract doses when compared to the group that was only given 20\% ethanol (Figure 5).

Table 2. Effect of ethyl acetate extract of Curcuma longa on antioxidant parameters, i.e., GSH, GPx, catalase, and SOD, in the kidney of alcohol induced female Wistar rats

\begin{tabular}{|c|c|c|c|c|}
\hline $\begin{array}{l}\text { Groups } \\
(\mathbf{n}=5)\end{array}$ & $\begin{array}{c}\text { GSH } \\
(\mu \mathrm{mol} / \mathrm{mg} \text { protein) }\end{array}$ & $\begin{array}{c}\text { GPx } \\
\text { (U/mg protein) }\end{array}$ & $\begin{array}{c}\text { SOD } \\
\text { (U/mg protein) }\end{array}$ & $\begin{array}{c}\text { Catalase } \\
\text { (U/mg protein) }\end{array}$ \\
\hline 1 & $1.96 \pm 0.06$ & $0.93 \pm 0.04$ & $25.74 \pm 1.17$ & $0.47 \pm 0.05^{\mathrm{b}}$ \\
\hline 2 & $1.29 \pm 0.06^{\mathrm{a}}$ & $0.71 \pm 0.03$ & $15.59 \pm 0.40^{\mathrm{a}}$ & $0.36 \pm 0.02^{\mathrm{a}}$ \\
\hline 3 & $1.77 \pm 0.08$ & $0.84 \pm 0.06^{\mathrm{b}}$ & $15.80 \pm 0.95^{\mathrm{a}}$ & $0.36 \pm 0.03^{\mathrm{a}}$ \\
\hline 4 & $1.65 \pm 0.07$ & $0.81 \pm 0.02^{\mathrm{b}}$ & $19.06 \pm 0.63^{b}$ & $0.45 \pm 0.06^{\mathrm{b}}$ \\
\hline 5 & $1.50 \pm 0.07^{\mathrm{b}}$ & $0.77 \pm 0.08^{\mathrm{a}}$ & $21.31 \pm 0.74$ & $0.44 \pm 0.06^{\mathrm{b}}$ \\
\hline 6 & $2.29 \pm 0.04$ & $0.79 \pm 0.06^{\mathrm{a}}$ & $23.96 \pm 1.28$ & $0.99 \pm 0.14$ \\
\hline
\end{tabular}

Note: Results are mean \pm SEM. a Controls are compared with ethanol-treated groups. $\mathrm{P}<0.05$, $\mathrm{b}$ the ethanol-treated group is compared with the $C$. longa extract + ethanol-treated groups. $\mathrm{p}<0.05$

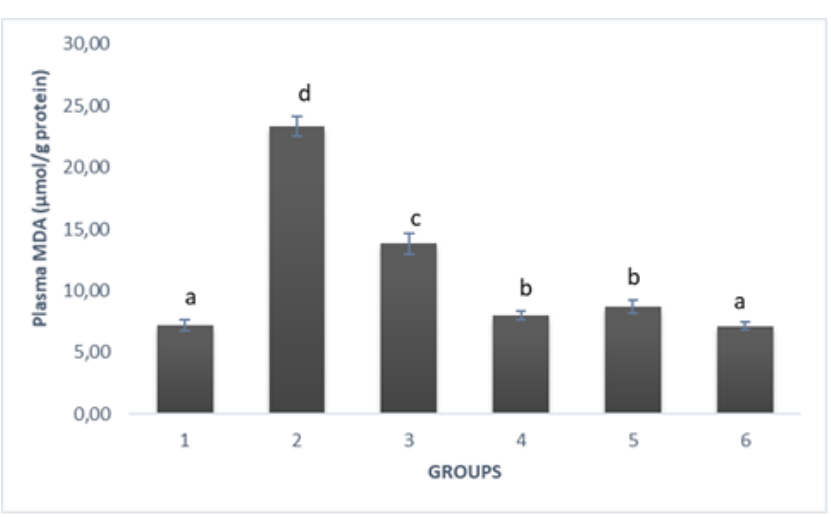

Figure 2. Effect of ethyl acetate extract of Curcuma longa on malondialdehyde in the plasma of alcohol-induced female Wistar rats. Results are Mean \pm SEM a Controls are compared with ethanol-treated groups. $\mathrm{P}<0.05, \mathrm{~b}$ the ethanol-treated group is compared with the $C$. longa extract + ethanol-treated groups. $\mathrm{p}<0.05$

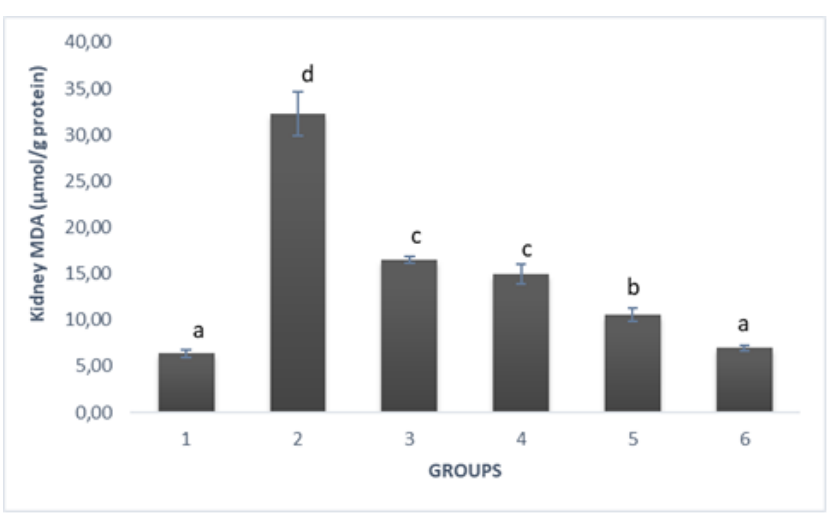

Figure 3. Effect of ethyl acetate extract of Curcuma longa on malondialdehyde in the kidney of alcohol-induced female Wistar rats. Results are Mean \pm SEM. a Controls are compared with ethanol-treated groups. $\mathrm{P}<0.05, \mathrm{~b}$ the ethanol-treated group is compared with the $C$. longa extract + ethanol-treated groups. $\mathrm{p}<0.05$

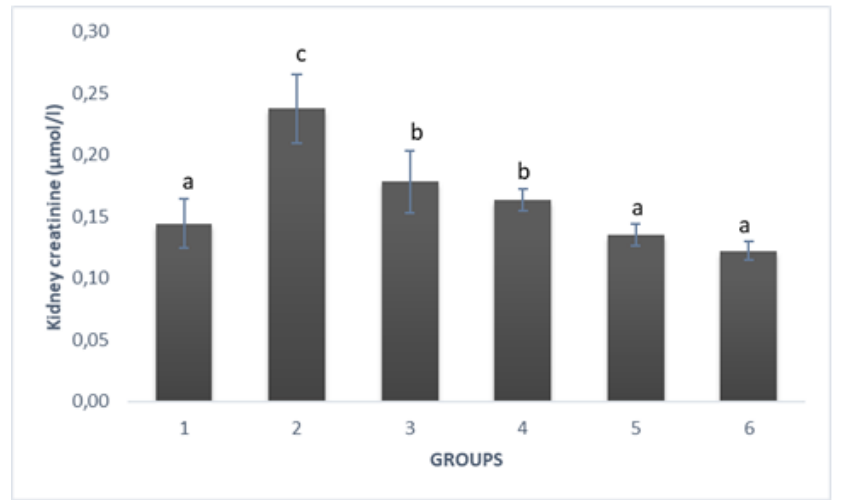

Figure 4. Effect of ethyl acetate extract of Curcuma longa on creatinine level in the kidney of alcohol-induced female Wistar rats. Results are Mean \pm SEM. a Controls are compared with ethanol-treated groups. $\mathrm{P}<0.05, \mathrm{~b}$ the ethanol-treated group is compared with the $C$. longa extract + ethanol-treated groups. $\mathrm{p}<0.05$

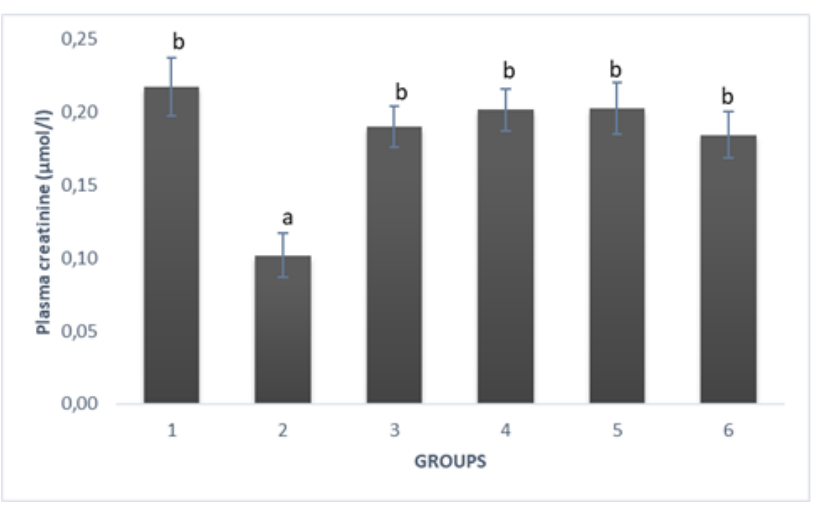

Figure 5. Effect of ethyl acetate extract of Curcuma longa on creatinine in the plasma of alcohol-induced female Wistar rats. Results are Mean \pm SEM. a Controls are compared with ethanoltreated groups. $\mathrm{P}<0.05, \mathrm{~b}$ the ethanol-treated group is compared with the $C$. longa extract + ethanol-treated groups $\mathrm{P}<0.05$ 
Extract administration led to a significant raise ( $\mathrm{P}$ $<0.05$ ) in plasma level of urea when the group was given $20 \%$ ethanol only compared to the normal control group, but there was a significant decline $(\mathrm{P}<0.05)$ in the group initially treated with various extract doses when compared to the group that was only given by $20 \%$ ethanol (Figure 6 ).

Treatment with extracts led to a significant decline (P $<0.05$ ) in kidney level of urea when the group was given $20 \%$ ethanol only compared to the normal control group, but there was a significant raise $(\mathrm{P}<0.05)$ in the group preadministered with various extract doses when compared to the group that was only given by $20 \%$ ethanol (Figure 7 ).

\section{Discussion}

Medicinal plants have therapeutic and pharmacological interest values, remaining the main source of active

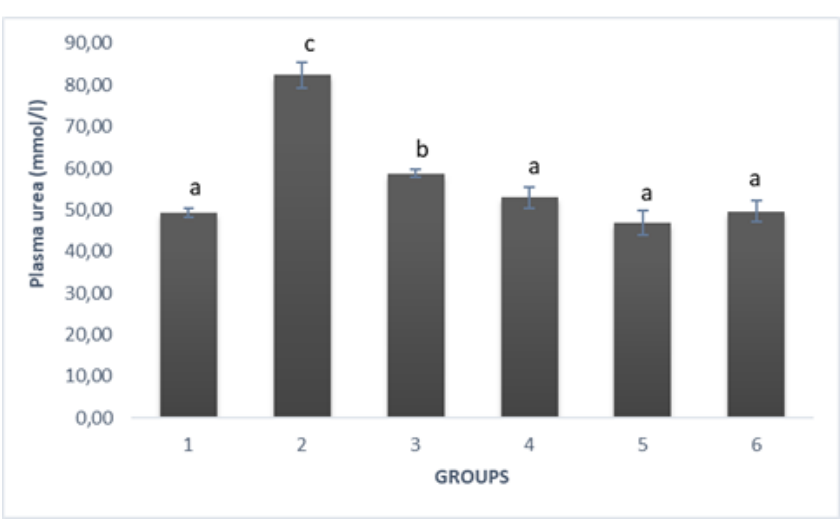

Figure 6. Effect of ethyl acetate extract of Curcuma longa on urea in the plasma of alcohol-induced female Wistar rats. Results are Mean \pm SEM. a Controls are compared with ethanol-treated groups. $\mathrm{P}<0.05, \mathrm{~b}$ the ethanol-treated group is compared with the C. longa extract + ethanol-treated groups. $\mathrm{P}<0.05$

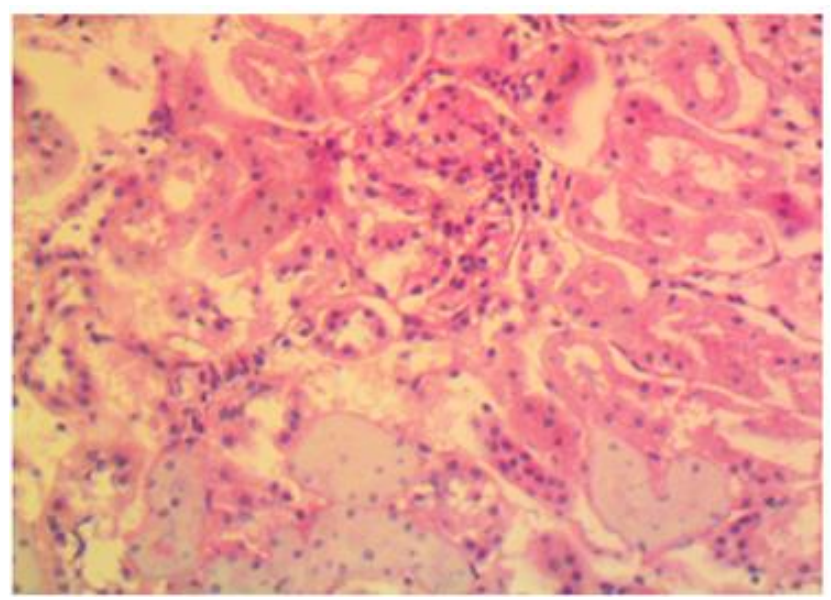

Figure 8. Section of the kidney showing moderate necrosis of tubular (arrow) and glomerular (arrowhead) epithelial cells and proteinaceous materials in the tubules (x400; $\mathrm{H} \& \mathrm{E})$ medicine from natural sources. Studies show that functional groups related to $C$. longa's chemical structure, including bis- $\alpha, \beta$-unsaturated $\beta$-dicone, two methoxy groups, two phenolic hydroxy groups, and two conjugated bonds, could have an important role in antiproliferative and anti-inflammatory activities. C. longa holds a keto-enol tautomer, in which the keto form is the predomination in acidic and neutral solutions, and enols form is the predomination in alkaline solutions. In this study, ethanol treatment significantly declined $(\mathrm{P}<0.05)$ in Reduced GSH content and SOD, GPx, and CAT activity in rat kidneys compared to the control group. These changes are significantly reversed with the treatment of $C$. longa extract.

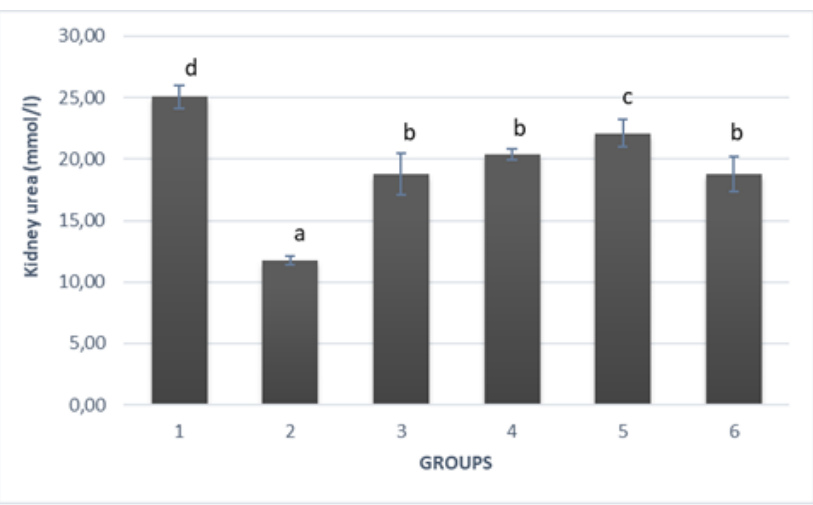

Figure 7. Effect of ethyl acetate extract of Curcuma longa on urea in the plasma of alcohol-induced female Wistar rats. Results are Mean \pm SEM. a Controls are compared with ethanol-treated groups. $\mathrm{P}<0.05$, $\mathrm{b}$ the ethanol-treated group is compared with the C. longa extract + ethanol-treated groups $\mathrm{P}<0.05$

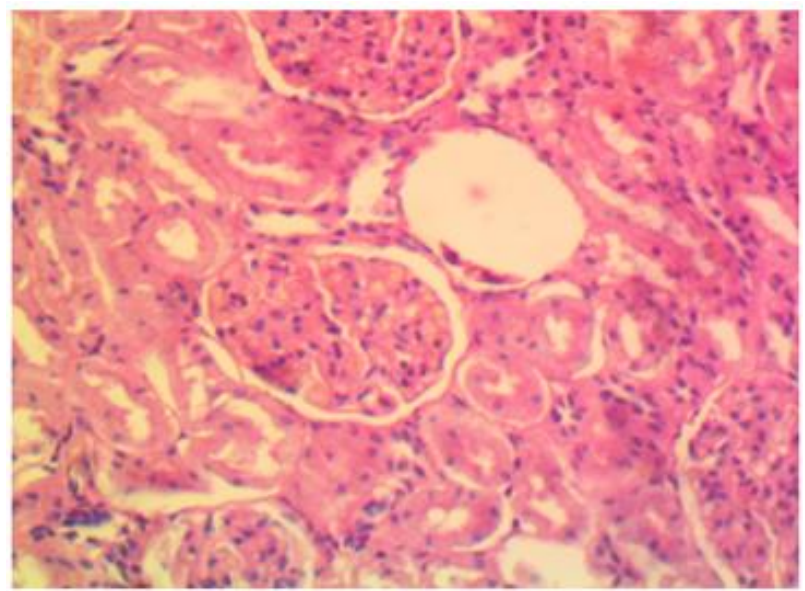

Figure 9. Section of the kidney showing severe necrosis of tubular (arrow) and glomerular epithelial cells (arrowhead) (x400; $\mathrm{H} \& \mathrm{E})$ 


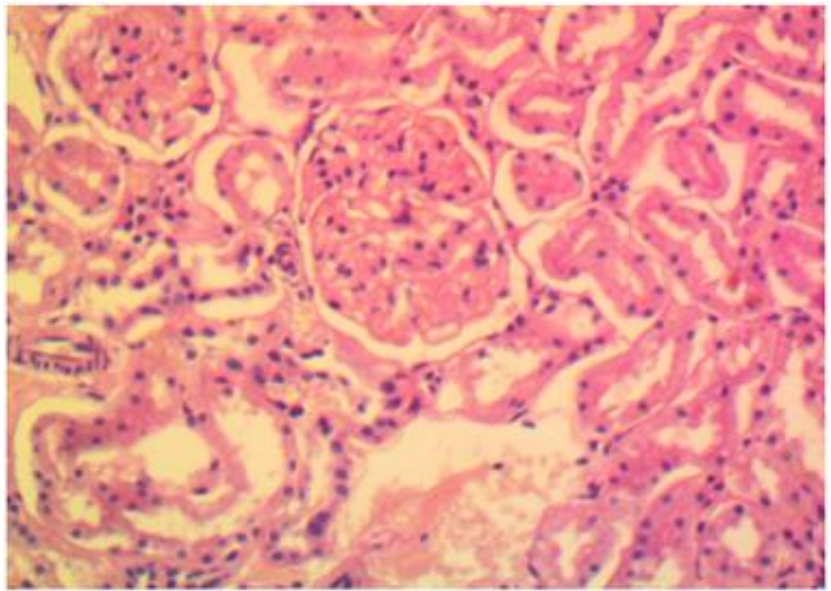

Figure 10. Section of the kidney showing mild necrosis of tubular (arrow) and glomerular (arrowhead) epithelial cells (x400; H \& E)

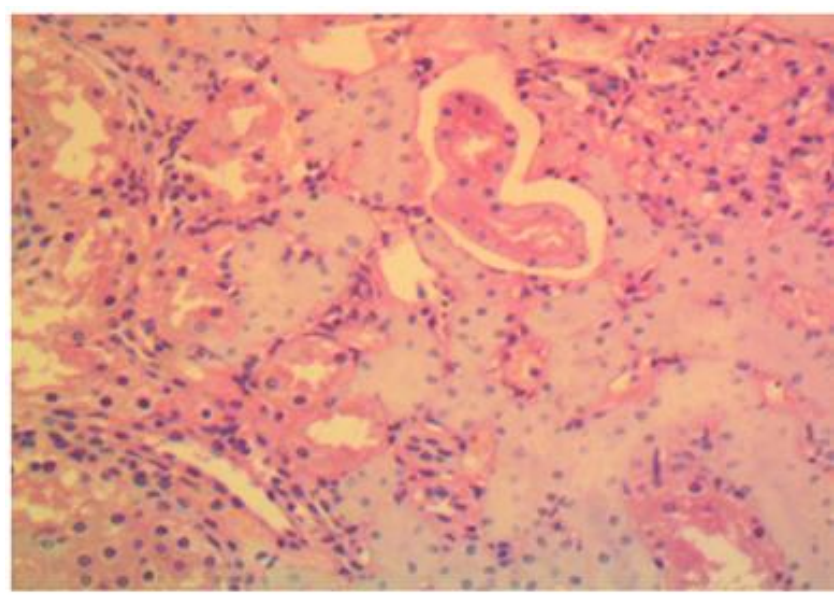

Figure 11. Section of a kidney showing moderate necrosis of tubular (arrow) and glomerular (arrowhead) epithelial cells ( $x 400$; $\mathrm{H} \& \mathrm{E})$

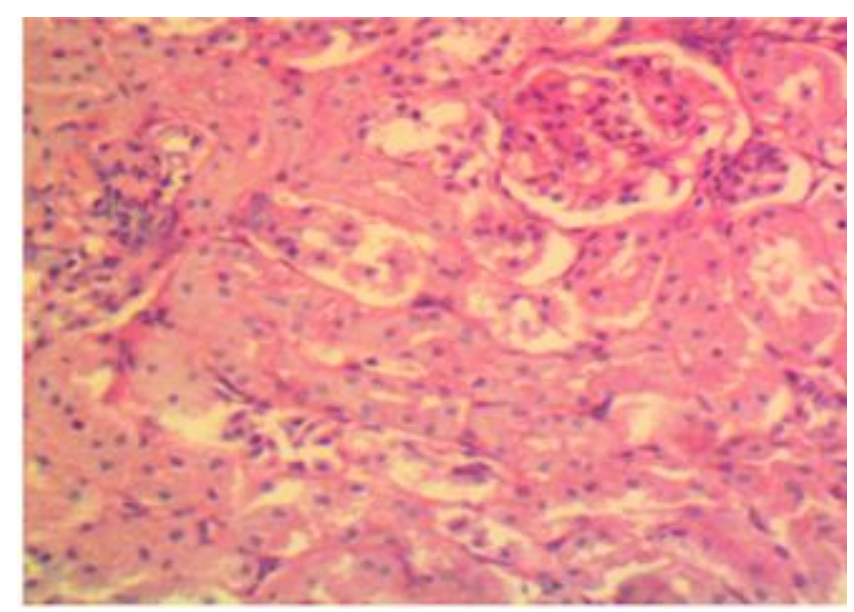

Figure 12. Section of the kidney showing moderate necrosis of tubular (arrow) and glomerular (arrowhead) epithelial cells (x400; $\mathrm{H} \& \mathrm{E})$

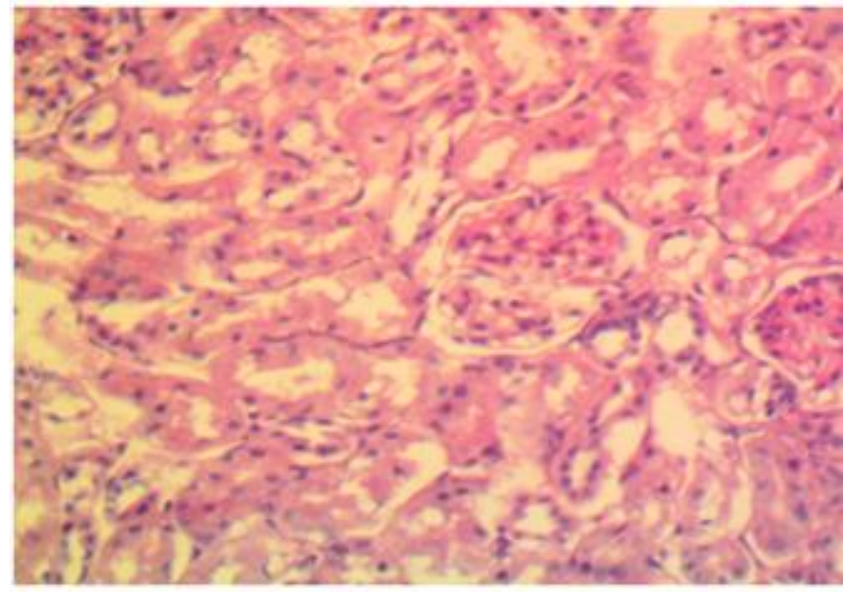

Figure 13. Section of the kidney showing moderate necrosis of tubular (arrow) and glomerular (arrowhead) epithelial cells (x400; $\mathrm{H} \& \mathrm{E})$

The deterrence of their synthesis may cause the activity reduction of these antioxidant enzymes by several reactive molecules produced during ethanol metabolism. Also, it could be the result of enzymatic protein oxidation by the induced reactive oxygen species. GSH plays an important role in flushing reactive oxygen species (ROS) and xenobiotic detoxification (Sen, 1997). The decline of endogenous antioxidants is clearly related to ethanolinduced oxidative stress, which is indicated by the cell's formation of toxic acetaldehyde and other reactive molecules. The attained results agree with Hussain et al. (2001) and Molina et al. (2011), showing that chronic ethanol treatment led to a significant decline in the GSH levels of kidneys. The monitored raise in declining GSH levels of mice treated with both $C$. longa and ethanol extracts is probably led by the integrated protective effect of the extract and endogenous GSH. It might also result from the generation of glutathione reductase, which has an important role in lessening oxidized glutathione to decrease at the expense of the NADPH and GSH-GSSG cycles in cells.

The extract administration also yielded a significant decline $(\mathrm{P}<0.05)$ in kidney activities of renal biomarkers, i.e., creatinine and urea, when the group was given by only $20 \%$ ethanol compared to the normal control group. Still, there was a significant raise $(\mathrm{P}<0.05)$ in the group treated with various dosages of extracts when compared to the group given $20 \%$ ethanol only. C. longa has been indicated to demonstrate strong anti-oxidants (Choi 2009). This might explain its anti-oxidant properties, which enable it to protect the kidneys against the adverse effects of free radicals and reactive oxygen species (ROS). Several systems that produce reactive aldehyde species and reactive oxygen species are activated by chronic alcohol consumption (Maher 1997). These results indicate that $C$. longa extract significantly impedes kidney disorders caused by ethanol. The plants under investigation are rich in 
polyphenol compounds, such as flavonoids, as part of their secondary metabolites (Ighodano et al. 2009). This might be explained by its antioxidant property, which prevents the kidney from the dangerous effects of free radicals and reactive oxygen species (ROS). Oxidative stress results from an intrusion of balance between the produced oxidant and the anti-oxidant that supports the oxidant. This is frequently generated by a raise in the production of reactive oxygen species (ROS) and declined activity of the antioxidant system (Reddy and Lokesh 1994). Based on Albano's (2002) and Cederbaum et al. (2009) opinions, chronic alcohol consumption induces the creation of free radicals and alters the level of enzymatic and nonenzymatic endogenous antioxidant systems. This leads to oxidative stress with a cascade of effects, thus, affecting the functional and structural integrity of cells and organelle membranes (Das et al. 2008). The tested ethyl acetate extract of $C$. longa has the ability to squelch alcoholinduced oxidative stress in mice.

The MDA level in the kidney significantly $(\mathrm{P}<0.05)$ declined in the group administered with various dosages of C. longa ethyl acetate extract before being given with $20 \%$ ethanol as compared to animals given with only $20 \%$ alcohol, but there was significant $(\mathrm{P}<0.05)$ raise when compared to the normal control group. Several systems that produce reactive aldehyde species and reactive oxygen species are triggered by chronic alcohol consumption (Maher 1997). This is in accordance with the findings in this study which exhibit a significant raise $(\mathrm{P}<0.05)$ in kidney malondialdehyde concentrations in mice administered with ethanol relative to controls. Alcohol metabolism that happens mainly in the liver and kidneys is indicated by the formation of free radicals and reactive oxygen species. Thus, the high level of MDA in the kidney could be featured in the production of free radicals, which generate membrane lipid peroxidation. In addition, the enzyme alcohol dehydrogenase $(\mathrm{ADH})$ is included in the main pathway for alcohol metabolism (Pronk et al. 2002). $\mathrm{ADH}$ alters alcohol into toxic acetaldehyde, whose interactions with cell proteins and lipids can lead to free radical formation and reno-cellular detriment. In contrast, compared to mice treated with ethanol only, a marked decrease $(\mathrm{P}<0.05)$ in kidney MDA levels is due to the cotreatment from $100 \mathrm{mg} / \mathrm{kg}$ bw/day to $350 \mathrm{mg} / \mathrm{kg}$ bw/day from $C$. longa extract with ethanol. According to the report of Kumar et al. (2004) and Kassuya et al. (2005), the decline of lipid peroxidation (LPO) levels is caused by the array of antioxidant phytochemicals found in plant extracts. In this study, the free radical scavenging activity shown by the extract is led by the antioxidant molecules in C. longa (Khatoon et al. 2005). A tremendous alteration of renal architecture is revealed by histopathological examination of the kidney section of the rats in the ethanol-treated group. Kidney cells were spoiled in mice treated with ethanol, while negligible detriment was seen in mice treated with extracts. The histological results show that it is a physiological recovery in renal tissue when groups treated with various extract doses show signs of protection against toxicity. Evidence can be seen from lessened tubular and glomerular epithelial necrosis.

In conclusion, from this study, it can be suggested that C. longa extract provides protection against alcoholinduced nephrotoxicity and oxidative detriment in mice, presumably by acting as an in vivo as scavengers of free radicals in vivo or by inducing antioxidant enzymes, drugs detoxifying enzymes, and hindering excessive stimulation from lipid peroxidation.

\section{ACKNOWLEDGEMENTS}

This work was performed in the department of biochemistry at the college of bioscience, Federal University of Agriculture Abeokuta. Furthermore, the authors would like to thank all the colleagues and staff for their contributions and valuable discussions that enriched this study.

\section{REFERENCES}

Albano E. 2002. Free radicals and alcohol-induced liver injury. In: Sherman D, Watson RR (eds.). Ethanol and the Liver: Mechanisms and Management, CRC Press, Boca Raton, FL. DOI: 10.3109/9780203301388-10

Cederbaum AI, Lu Y, Wu D. 2009. Role of oxidative stress in alcoholinduced liver injury. Arch Toxicol 83: 519-548.

Choi HY. 2009. Antioxidant activity of Curcuma longa L., novel foodstuff. Mol Cell Toxicol 5 (3): 5237-242.

Das L, Vinayak M. 2008; Anti-carcinogenic action of curcumin by activation of antioxidant defense system and inhibition of NF-kappa B signaling in lymphoma-bearing mice. Biosci Rep 32: 161-170.

Das SK, Nayak P, Vasudevan DM. 2008. Consequences of ethanol consumption. J Indian Soc Toxicol 1 (1): 1-10.

Deodhar SD, Sethi R, Srimal RC. 1980. Preliminary studies on antirheumatic activity of curcumin. Ind J Med Res. 71: 632-634.

Guyton AC. 1992. Human Physiology and Mechanisms of Disease. 5th ed. W.B. Saunders, Philadelphia.

Hussain K, Scott BR, Reddy SK, Somani SM. 2001. Chronic ethanol and nicotine interaction on rat tissue antioxidant defense system. Alcohol 25: 89-97.

Ighodaro OM, Mairiga JP, Adeyi AO. 2009. Reducing and Antiproxidant profiles of flavonoids in Ocimum gratissimum. Intl J Chem Sci 2 (1): 85-89.

Kassuya CA, Leite DE, de Melo LV, Rehder VL, Calixto JB. 2005. Antiinflammatory properties of extracts, fractions and lignans isolated Phyllanthus amarus. Planta Medica 71 (8): 721-726.

Khatoon S, Rai V, Rawat AK, Mehrotra S. 2005. Comparative pharmacognostic study of three Phyllanthus amarus species. J Ethopharmacol 104: 79-86.

Knott C, Bell S, Britton A. 2015. Alcohol consumption and the risk of type 2 diabetes: a systematic review and dose-response meta-analysis of more than 1.9 million individuals from 38 observational studies. Diabetes Care 38: 1804-1812.

Knott C, Bell S, Britton A. 2015; Alcohol Consumption and the risk of Type 2 Diabetes: A systematic review and Dose-Response Metaanalysis of More than 1.9 Million individuals from 38 Observational Studies. Diabetes Care 38 (9): 1804-12.

Koning SH, Gansevoort RT, Mukamal KJ. 2015. Alcohol consumption is inversely associated with the risk of developing chronic kidney disease. Kidney Intl 87(5): 1009-1016.

Kumar Hari KB, Kuttan R. 2004. Protective effect of an extract of Phyllanthus amarus against radiation-induced damage in mice. $\mathrm{J}$ Radiat Res 45: 133-139.

Latchoumycandane C, Nagy LE, McIntyre TM. 2015. Myeloperoxidase formation of PAF receptor ligands induces PAF receptor-dependent 
kidney injury during ethanol consumption. Free Radic Biol Med 86: 179-190.

Latchoumycandane C, Nagy LE, McIntyre TM. 2015. Myeloperoxidase formation of PAF receptor ligands induces PAF receptor-dependen kidney injury during ethanol consumption. Free Radic Biol Med 86: 179-190.

Lu Y, Cederbaum AI. 2009. CYP2E1 and oxidative liver injury by alcohol. Free Radic Biol Med 44 (5): 723-738.

MaherJJ. 1997. Exploring Alcohol effects on Liver Functions. Alcohol Health Res World 21 (1): 5-12.

Meng Q, Wong Y, Chen J, Ruan R. 2007. Age-related changes in mitochondrial function and anti-oxidative enzyme activity in Fischer 344 rats. Mech Ageing Dev 128: 286-292.

Molina-Jijón E, Tapia C, Zazueta M, El Hafidi ZL, Zatarain-Barrón R, Hernández-Pando ON, Medina-Campos G, Zarco-Márquez I, Torres J, Pedraza-Chaverri. 2011. Curcumin prevents $\mathrm{Cr}(\mathrm{VI})$-induced renal oxidant damage by a mitochondrial pathway. Free Radic Biol Med 51: $1543-1557$
Reddy AC, Lokesh BR. 1994. Effect of dietary turmeric (Curcuma longa) on iron-induced lipid peroxidation in the rat liver. Food Chem Toxicol 32 (3): 279-283.

Parekh RS, Klag MJ. 2001. Alcohol: role in the development of hypertension and end-stage renal disease. Curr Opin Nephrol Hypertens 10: 385-390.

Pronk P, Bardina L, Satanovskaya V, Kuzmieh A, Zitmakin. 2002. Effects of chronic alcohol consumption on ethanol and acetaldehyde metabolizing systems in rats' gastrointestinal tract. Alcohol Alcoholism 37 (3): 229-235.

Purohit PK, Kondev J, Phillips R. 2003. Mechanics of DNA packaging in viruses. Proc Natl Acad Sci USA 100 (6): 3173-3178.

Rhoades R, Pflanzer R. 1992. Human Physiology. 2d ed. Saunders College Publishing, Fort Worth, USA.

Sen CK. 1997. Nutritional Biochemistry of cellular glutathione. Nutr Biochem 8: 660-672.

White SL, Polkinghorne KR, Cass A, Shaw JE, Atkins RC, Chadban SJ. 2009. Alcohol consumption and 5-year onset of chronic kidney disease: The AusDiab study, Nephrol. Dialysis Transplant 24 (8): 2464-2472. 